\title{
A Teoria da Argumentação na Língua e o trabalho do revisor de textos
}

\author{
The Theory of Argumentation in the Language and the work of the reviewer of texts
}

\author{
Leci Borges Barbisan \\ Pontifícia Universidade Católica do Rio Grande do Sul - Porto Alegre - Rio Grande do Sul - Brasil \\ Vanessa Fonseca Barbosa \\ Pontifícia Universidade Católica do Rio Grande do Sul - Porto Alegre - Rio Grande do Sul - Brasil \\ Tamiris Machado Gonçalves \\ Pontifícia Universidade Católica do Rio Grande do Sul - Porto Alegre - Rio Grande do Sul - Brasil
}

$\diamond$

\begin{abstract}
Resumo: Este artigo apresenta uma discussão acerca da atuação do profissional de Letras como revisor e de que modo a Teoria da Argumentação na Língua, criada por Oswald Ducrot, pode servir de aporte teórico-metodológico para esse profissional em sua área de atuação. Em vista disso, apresenta uma análise de um trabalho de revisão que demonstra conflito quanto ao que seria a construção textual adequada, bem como ao que seria uma intervenção linguística aceitável por parte de um revisor de textos. Através do exemplo analisado, e das discussões promovidas ao longo do texto, busca-se evidenciar a importância de o profissional de revisão apresentar um aporte teórico-metodológico que sustente linguisticamente seus argumentos.
\end{abstract}

Palavras-chave: Teoria da Argumentação na Língua; Análise de textos; Revisão textual

\begin{abstract}
This article presents a discussion on the professional practice of the text editor and the way in which the Theory of Argumentation in Language, founded by Oswald Ducrot, can provide a theoretical and methodological foundation for professionals in this area of expertise. In view of this, we present an analysis of an editing project that demonstrates a conflict regarding the appropriate textual construction, as well as any acceptable linguistic intervention on the part of the text editor. Through the example analyzed, and the discussions advanced over the course of the paper, we aim to provide evidence for the importance of professional editors to present a theoretical-methodological foundation that linguistically supports their arguments.
\end{abstract}

Keywords: Theory of Argumentation in Language; Text analysis; Text editing

\section{Introdução}

Sabe-se que a maioria dos sujeitos interessados na formação do profissional de Letras busca os cursos oferecidos pelas Universidades públicas ou privadas do país e opta pela licenciatura - preferencialmente os que pretendem exercer o magistério futuramente - ou pelo bacharelado, sobretudo aqueles que têm maior interesse pela pesquisa acadêmica. Ainda assim, na prática, tem-se conhecimento de que nenhuma das alternativas (magistério e pesquisa) exclui a atuação do profissional na outra.

Todavia, independentemente dessa escolha, é de conhecimento comum também o fato de que grande parte dos profissionais da área de Letras já atuou ou provavelmente atuará em um terceiro campo de sua formação: a atividade de revisor de textos. Tal atuação justifica-se principalmente porque há considerável procura pelo trabalho do revisor advinda de pessoas das várias áreas do conhecimento, visto que, em teoria, os indivíduos formados em Letras dominam as competências de ler, escrever e corrigir textos.

Além disso, são comuns, por exemplo, durante arguições de Trabalhos de Conclusão de Curso (TCC), de defesas de monografias ou mesmo de dissertações de mestrado e teses de doutorado, pareceres do seguinte teor: "Seu texto está confuso, por isso é importante que o envie à revisão" ou "As coisas que você apresentou oralmente não estão de acordo com as que você entregou no material impresso, logo é necessário que revise seu 
texto" etc. Situações como essas, no decorrer das vivências acadêmicas, permitem constatar que as observações realizadas por bancas avaliadoras, com relação específica ao texto escrito e à importância da atividade de revisão, têm sido muitas e, na maioria das vezes, significativas. Isso, em consequência, destaca a relevância do papel desempenhado pelo profissional da revisão.

No entanto, mesmo com o aparente espaço no mercado de trabalho para o revisor, até o momento, temse conhecimento de apenas um curso de Graduação em revisão textual, no Brasil, oferecido pela Universidade Federal de Pelotas - UFPel - denominado Curso de bacharelado em Letras - Redação e Revisão de textos ${ }^{1}$. O bacharel dessa instituição possui formação exclusiva para atuar como profissional de revisão textual. Como se vê, trata-se apenas de um curso de formação em nível de Graduação. Por outro lado, em rápida pesquisa pela web, percebe-se a multiplicidade de cursos de pós-graduação lato sensu, quando se trata do trabalho de revisão, o que parece indicar que a busca por esse trabalho é expressiva e que os cursos de especialização esforçam-se para dar conta da demanda do mercado à procura de revisor profissional.

Tamanha visibilidade do trabalho de revisão poderia fazer supor que há, nos espaços acadêmicos, variadas pesquisas sobre essa atividade. No entanto, é necessário destacar que são poucos os estudos que se debruçam sobre o trabalho do revisor de textos em contexto acadêmico. Ao realizar uma pesquisa no banco de Teses e Dissertações da Coordenação de Aperfeiçoamento de Pessoal de Nível Superior (CAPES) com as seguintes palavras-chave: revisão de textos, revisor e revisão textual, encontrou-se uma lista com cento e trinta e nove trabalhos, dos quais somente doze $^{2}$ (oito dissertações de mestrado e quatro teses de doutorado) tratavam especificamente da atividade de revisão textual e consideravam contribuições advindas de perspectivas linguísticas em sua investigação.

\footnotetext{
1 O Projeto Pedagógico do Curso, bem como mais informações a seu respeito estão disponíveis no seguinte endereço eletrônico: http:// wp.ufpel.edu.br/letras-bacharelado/producao-e-revisao-textual/curso/. Acesso em 10 de junho de 2014.

2 Seguem alguns exemplos dos trabalhos encontrados com a seguinte ordem: título, autor, instituição e ano em que foram desenvolvidos: 1) O processo de revisão textual na construção da textualidade através da focalização das máximas de Grice, de Clarice Vaz Peres Alves (UCPel, 2002); 2)Processos de revisão e reescritura em textos narrativos de alunos de quinta série do ensino fundamental, de Érica Maio Taveira (UNESP, 2006); 3) O papel da revisão textual em textos reescritos por crianças, de Margareth Correia Fagundes Costa (UFPE, 2010) e 4) $O$ impacto da revisão de textos sobre a interface semântica-pragmática, de Paulo Ledur (PUCRS, 2006).

3 Sabe-se que a noção "bons textos" é ampla e pode ter diferentes formas de compreensão, no entanto, para discuti-la com a profundidade devida, seria necessário outro trabalho com objetivos diferentes do aqui proposto. Por isso, neste texto, tomar-se-á como um bom texto aquele que é desenvolvido em coerência com suas proposições, ou seja, uma produção textual que apresente arguição clara, encadeamento coeso, fazendo uso devido da pontuação, bem como da utilização adequada da linguagem escrita.
}

Grande parte desses trabalhos tem nas contribuições da Linguística Textual o aporte teórico-metodológico para as análises realizadas, bem como tem por objeto de investigação o trabalho de revisão do professor de produção textual em textos de alunos, ou seja, estudos que demonstram a revisão como atividade circunscrita ao universo escolar da educação básica, mas que não tratam do profissional que revisa textos acadêmicos. Assim, se quase não há pesquisas que tratem da formação e atuação do revisor de textos, e a procura pela atividade parece ser grande, é possível concluir que a maior parte dos revisores que atua profissionalmente age muito mais guiada por "instinto" do que significa a formação/organização de bons textos, do que propriamente embasada por aportes teórico-metodológicos linguísticos, tendo em vista que, nos cursos de Graduação, normalmente, há poucas disciplinas que têm por objeto de estudo o texto e suas particularidades.

Desse modo, o presente artigo tem por finalidade mostrar que há na Teoria da Argumentação na Língua (ANL) uma possibilidade linguística de ancoragem teórica e metodológica para o trabalho do profissional revisor. Acredita-se que essa teoria pode potencializar o trabalho do revisor, haja vista sua possibilidade de comprovar, através da língua, como se dá o processo de formação de bons textos ${ }^{3}$, o que tende a auxiliar - não só o profissional em sua atividade laboral, mas também o autor do texto revisado - a compreender os motivos que justificam as intervenções comumente realizadas e/ou indicadas pela revisão em suas produções textuais.

Para alcançar os objetivos pretendidos, este trabalho está dividido em uma seção que tratará do referencial teórico da ANL, seguido por um item que discorrerá sobre a atividade do revisor de textos. No fim, apresentar-se-á um exemplo que busca comprovar o potencial da Teoria da Argumentação na Língua em uma atividade prática de revisão textual.

\section{A Teoria da Argumentação na Língua}

A Linguística, como grande área de pesquisa, oferece uma gama de teorias que pretendem explicar e descrever como se dá o processo de construção dos sentidos. Dentre elas, encontra-se a Semântica Argumentativa, que visa estudar a linguagem em uso e compreende que a construção de sentidos faz-se a partir das relações que se dão no âmbito linguístico. Assim, nessa concepção, o discurso constrói sentidos que podem ser explicados na e pela língua por meio das relações entre os signos, o que gera os encadeamentos que se encontram no discurso.

Pode-se dizer que a Teoria da Argumentação na Língua é mais um grande trabalho de pesquisa, do que uma teoria concluída/encerrada, uma vez que se encontra 
em contínuo desenvolvimento. Nascida na França, na figura do filósofo e linguista Osvald Ducrot e na de JeanClaude Ascombre, é possível falar, até o momento, em três fases: forma standard (1983), teoria da polifonia e teoria dos topoi (1990), bem como teoria dos blocos semânticos, tese de Marion Carel, defendida em 1992. É fundamental destacar que o âmago da teoria consiste na defesa de que a língua é essencialmente argumentativa e que as relações estabelecidas pelas palavras orientam a construção do seu caráter argumentativo.

Faz-se necessário esclarecer também que, para essa teoria, a palavra argumentação toma uma acepção diferente daquela difundida pela Retórica. Em seu artigo intitulado Argumentação retórica e argumentação linguística ${ }^{4}$, Ducrot (2009) explica que argumentação retórica é "a atividade verbal que visa fazer alguém crer em alguma coisa". É a persuasão por meio do discurso. É a relação de causa e consequência em que argumentos levam a conclusões. Já a argumentação linguística é a orientação discursiva que a palavra carrega ou a instrução contida na significação da palavra que orienta para uma argumentação pela língua. Assim, para a Teoria da Argumentação na Língua, a palavra argumentação referese à orientação argumentativa.

No discurso, o significado de uma palavra, por exemplo, orienta para uma continuação que pode ter ou não um seguimento, no que tange ao seu sentido, dependendo das palavras que forem combinadas. Dessa maneira, A não tem sentido enquanto não estiver relacionado a B. Não é possível inferir logicamente coisas de $\mathrm{A}$ ou de $\mathrm{B}$ porque eles não têm sentido pleno, completo, por si sós. O sentido acontece, portanto, na relação entre signos da língua. Isso significa dizer que é pela combinação de termos que se edifica o sentido. Este advém, pois, da relação que existe entre os elementos do sistema linguístico. Essa noção tem bases no estruturalismo saussuriano, conforme é possível perceber na citação que segue:

[...] para Saussure, el significado de una expresión reside en las relaciones de esa expresión con otras expresiones de la lengua. Como es sabido, Saussure define la lengua como un sistema de signos. Cada signo está constituído por elementos: un significante y un significado. Ahora bien, para Saussure el significado de un signo es el conjunto de relaciones de ese signo con otros signos de la lengua. Esto significa que el significado de $\mathrm{E}^{1}$ está constituído por las relaciones que $\mathrm{E}^{1}$ tiene con $\mathrm{E}^{2} \mathrm{y}$ con $\mathrm{E}^{3}$. (DUCROT, 2005, p. 11)

\footnotetext{
4 DUCROT, Oswald. Argumentação retórica e argumentação linguística. Letras de Hoje, Porto Alegre, v. 44, n.1, p. 20-25, 2009.

5 A citação, em sua forma original, utiliza os termos donc (portanto) e pourtant (no entanto), mantendo a nomenclatura em francês.
}

Assim, a argumentação linguística está nos "segmentos de discurso constituídos pelo encadeamento de duas proposições A e C, ligadas implícita ou explicitamente por um conector do tipo portanto ou no entanto 5 ". Os seguintes exemplos podem ilustrar as colocações anteriores: a) "Maria prometeu que viria ao meu aniversário e veio"; e b) "Maria prometeu que viria ao meu aniversário e não veio" e, consequentemente, os seguintes encadeamentos: a) "prometer portanto cumprir"; e b) "prometer no entanto não cumprir". Como se pode observar, os conectores explicitam a natureza da argumentação.

A argumentação acontece, então, através do encadeamento de dois segmentos discursivos unidos pelo conector portanto, chamado normativo, pois obedece à orientação da palavra construindo com ela uma relação de continuação no que tange ao sentido, isto é, combinação de palavras linguisticamente possíveis; no entanto é chamado conector do tipo transgressor, uma vez que infringe a norma e quebra o fluxo da orientação argumentativa contida no discurso. Desse modo, as palavras relacionadas se complementam para formar o sentido, de tal sorte que o conector tem de expressar o rompimento ou a continuidade dessa relação.

Observe-se que os conectores apresentados são abstrações, protótipos das relações de sentido. Dessa forma, portanto representa todos os conectivos que marcam as relações conclusivas, como o conector explicita. Do mesmo modo, no entanto contempla todas as relações adversativas. Na Gramática Tradicional, é possível citar como exemplo as conjunções mas, porém, não obstante, entre outras, classificadas como adversativas e portanto, por isso, por conseguinte, entre outras, denominadas como conclusivas.

Ainda sobre os fundamentos da ANL, é possível considerar uma publicação de 1990, intitulada Polifonía y argumentación, como uma das mais importantes até o momento, tendo em vista que apresenta as bases do estudo em foco. O referido trabalho é fruto de uma série de conferências proferidas por Oswald Ducrot na cidade de Cali (Colômbia) no ano de 1988 e reúne as ideias basilares da Teoria da Argumentação na Língua, mais especificamente de sua primeira fase.

Já no capítulo inicial da obra mencionada, intitulado Primera Conferencia, Ducrot expõe que o principal objetivo da nascente ciência é opor-se à concepção tradicional de sentido, haja vista que esta o compreende a partir de três indicações: objetiva, subjetiva e intersubjetiva. A primeira é aquela que toma o sentido como representação objetiva da realidade; a segunda o vê como resultante da atitude do interlocutor frente à realidade e, por fim, a intersubjetiva refere-se às relações do locutor com o(s) interlocutor(es) a que(m) se dirige. 
Esse raciocínio é ilustrado pelo seguinte exemplo apontado por Ducrot na frase "Pedro é inteligente", na qual o aspecto objetivo refere-se a uma descrição de Pedro; o subjetivo a uma espécie de admiração por parte do locutor em relação a Pedro, e o intersubjetivo diz respeito à possibilidade de o locutor solicitar ao seu destinatário determinada atitude em relação a Pedro que poderia ser a de confiança, por exemplo, uma vez que, admitindo-se que Pedro é inteligente, o destinatário poderia aceitá-lo como um ser eficiente na execução de determinada atividade.

A crítica de Ducrot às considerações delineadas pela concepção tradicional de sentido fundamenta-se, basicamente, em dois argumentos: primeiro, o autor não entende que a linguagem possa ter uma parte objetiva e, segundo, o acesso à realidade não ocorre de modo direto, isento de juízos de valor, mas sim se dá através dos olhares do locutor, o que demonstra a íntima e interdependente relação entre os aspectos subjetivo e intersubjetivo.

Dito de outro modo, o autor pressupõe ponderar sobre o fato de que as palavras não contêm sentido denotativo/ literal, haja vista que, se o tivessem, significariam por si sós, e não poderiam, a depender da combinação com outras palavras, assumir outros sentidos. Admitir que as palavras significam aprioristicamente seria oporse à filiação existente entre a teoria ducrotiana e os fundamentos do linguista Ferdinand de Saussure, para o qual os elementos linguísticos só se definem no interior do sistema da língua, pelas relações que estabelecem.

Por meio da noção de valor, Saussure mostra que os signos não têm sentidos determinados aprioristicamente, mas sim os constroem na relação que estabelecem com outros signos na estrutura da língua, já que "o valor de qualquer termo que seja está determinado por aquilo que o rodeia" (SAUSSURE, 2006, p. 135). A concepção de Saussure de que o sentido advém da relação pode ser visível na citação dos Escritos de Linguística Geral que segue:

Assim como, no jogo de xadrez, seria absurdo perguntar o que seria uma dama, um peão, um bispo ou um cavalo, considerados fora do jogo de xadrez, assim também não tem sentido, quando se considera verdadeiramente a língua, buscar o que é cada elemento por si mesmo. Ele nada é além de uma peça que vale por oposição às outras, segundo certas convenções (SAUSSURE, 2012, p. 63) (grifo do autor).

As palavras de Saussure evidenciam a importância de o linguista sempre ponderar a respeito da relação entre os signos no interior do sistema da língua, não os considerando jamais como elementos isolados, uma vez que um signo por si só não constrói sentido. A ANL, consequentemente, como teoria semântico-sintagmática, vai afirmar que "A língua constitui-se, então, de algumas relações - observáveis ou por introspecção, ou por uma espécie de estudo distribucional - entre elementos da linguagem" (DUCROT, 1987, p. 64).

Essas colocações demonstram a relevância dos postulados da Teoria da Argumentação na Língua para os estudos linguísticos, pois comprovam que é através $d a$ e pela língua que as relações se configuram e edificam o discurso. Nesse sentido, é importante destacar que, para a ANL, a significação das palavras corresponde a uma abstração, seria seu mínimo valor possível, mas não significante, que precisa da relação com os demais elementos para produzir o sentido. Assim, é ímpar perceber a maleabilidade da linguagem que, através da combinação dos seus elementos sígnicos, permite a construção dos sentidos.

Nessa perspectiva, portanto, o discurso é o resultado de utilização da língua. Logo, é pela observação do discurso que se chega à língua e esta, por sua vez, explica-o, tal como uma construção teórica que é. Cabe, então, ao linguista e aos profissionais da área de Letras em geral saber reconhecer e determinar as relações advindas das combinações da língua, as quais são capazes de materializar toda e qualquer manifestação discursiva.

Antes de se concluir esta pequena exposição sobre algumas das importantes considerações que fundamentam a Teoria da Argumentação na Língua, explicitar-se-á, ainda, que Ducrot esclareceu, no texto intitulado $A$ semântica argumentativa pode se filiar a Saussure?, que chegou aos postulados saussurianos quando teve de substituir um colega em um curso que continha em seu programa o tema "estruturalismo". Ao estudar as considerações do mestre genebrino, Ducrot reconheceu a definição de valor intimamente relacionada com a de alteridade em Platão, mais especificamente em $O$ sofista.

Em Le sophiste, Platão (cf. Cordero, 1993, p. 04) explica que "o que é isolado degenera e morre". O filósofo grego, em suas reflexões, refere-se à realidade, trata do ser e do não ser e não fala especificamente sobre a linguagem, mas as considerações que levanta permitem cogitá-la. O conceito de alteridade em Platão expõe que nada é isolado, tal qual se pode ponderar sobre a linguagem, pois é de conhecimento comum que ninguém comunica por palavras isoladas. Mesmo que se tentasse verbalizar um dicionário inteiro, as palavras isoladas nada comunicariam, isto porque a palavra sozinha não basta para a expressão de um pensamento - faz-se necessário colocá-la em interação com outras palavras para que se consiga produzir sentido.

Essa noção de alteridade, da necessidade do outro para que a relação e o sentido se estabeleçam, permeia a obra de Saussure, sobretudo no capítulo do valor, como já exposto neste texto. Ducrot, por sua formação 
filosófica e por sua inscrição no estruturalismo, ancora-se também nessa noção de relação - identificada em Platão e em Saussure, sobre a qual tanto se insistiu nesta seção justamente com o intuito de demonstrar que nela está (ou deveria estar) o âmago de uma análise linguística.

$\mathrm{Na}$ sequência da escrita, então, tratar-se-á de alguns princípios da atividade de revisão textual com vistas a mostrar, posteriormente, através de um exemplo prático, como as considerações da ANL podem auxiliar o trabalho do revisor de textos e, consequentemente, potencializar produções textuais revisadas. Acredita-se ser importante esse tipo de reflexão, tendo em vista que, como se sabe, escrever é uma atividade complexa e há um número significativo de dificuldades quanto ao desenvolvimento da competência escrita ${ }^{6}$.

\section{A Atividade de trabalho do revisor de textos acadêmicos: algumas considerações}

Antes de se discorrer sobre a atividade do revisor de textos, ponderar-se-á brevemente sobre a atividade de produção textual e sua importância principalmente no universo acadêmico. Assim, inicia-se, destacando que uma das mais eficientes formas que o homem encontrou de perpetuar e difundir o conhecimento está na divulgação escrita de seus achados. A maior parte dos resultados de pesquisas e vários pensamentos desenvolvidos está registrada nos múltiplos tipos de textos existentes. A escrita encontra, portanto, nessas finalidades, algumas de suas mais valiosas contribuições: o registro das descobertas humanas.

Por outro lado, independente de sua importância, é frequente também a constatação de que muitos estudantes têm dificuldades para escrever e conseguir organizar textualmente suas ideias e seus textos. Essa consideração é universal no que diz respeito ao grau acadêmico dos alunos, já que, como se sabe, há textos malformados, isto é, apresentando problemas de diversas ordens (lexical, sintática, semântica etc.), não só no ensino básico, mas também disponíveis na publicação de revistas e livros conceituados no mercado, escritos por autores com pósgraduações em diversas áreas do conhecimento.

Logo, é no impasse entre a necessidade de escrever - principalmente imposta para sobrevivência no atual universo acadêmico de pesquisas e publicações em massa - e as dificuldades encontradas nessa tarefa que o revisor de textos vai conquistando seu espaço no mercado de

\footnotetext{
6 Há inúmeros artigos e diversas pesquisas que demonstram que a maior parte dos estudantes, desde a escolaridade básica até o nível superior, tem dificuldades para escrever. Como exemplo dessa questão, indicase o seguinte artigo, disponível em http://www.planetaeducacao.com.br/ portal/artigo.asp?artigo=2092. Acesso em $1^{\circ}$ de julho de 2014 .
}

trabalho, conforme se destacou na introdução deste artigo, embora seja preciso dizer também que grande parte do trabalho de revisão acontece de forma velada, ou seja, por acordo particular entre o autor e o revisor, sem que mais alguém tome conhecimento de que determinado texto passou por revisão.

Outra questão que cabe retomar relaciona-se ao fato de que os espaços acadêmicos que tratam especificamente de produção, avaliação e correção de textos nos cursos de graduação em Letras ainda são pequenos. Isso faz com que a maior parte dos revisores que atua não tenha base teórica linguística suficiente, tanto para o desenvolvimento da tarefa, quanto para o diálogo com o autor do texto revisado, no momento de justificar suas intervenções ou sugestões de alterações no texto, o que acarreta algumas consequências negativas, das quais se mencionarão duas.

Em primeiro lugar, por acreditar que se trata de um trabalho automático, com pouco ou quase nenhum desenvolvimento de raciocínio, alguns autores, quando procuram o trabalho do revisor, pensam que revisar é uma tarefa meramente mecânica que exige do profissional da área de Letras uma simples aplicação de regras gramaticais e ortográficas, as quais o graduado deve ter memorizadas, bastando "aplicá-las no texto" para garantir a sua boa produção e, por conseguinte, sua revisão. Isso está intimamente relacionado ao segundo ponto: a desvalorização da atividade, pois, justamente por pensar que se trata de algo simples e praticamente automático, a maior parte dos autores que busca pelo profissional de revisão de textos não acredita que o seu trabalho deva ser valorizado financeiramente.

No entanto, é fundamental esclarecer que a atividade de revisão de textos em nada é (ou não deveria ser!) uma tarefa mecânica de arranjo ortográfico e gramatical, uma vez que tratar somente desses tópicos não dá conta de modificar os problemas que o texto apresenta, com vistas a tornar as ideias desejadas explícitas nos encadeamentos construídos linguisticamente. Faz-se tal afirmação porque, como se procurou demonstrar, a organização da língua e, em consequência, de textos, está na relação entre as palavras e no modo como se organizam. Acreditase, então, que revisar um texto pressupõe superar essa visão errônea do trabalho e compreender que a escrita e a avaliação do texto enquanto processos dinâmicos e complexos devem ser submetidos a leituras e releituras, tanto por parte do autor como do revisor, buscando na língua os encadeamentos necessários para as considerações expostas textualmente.

Defende-se, portanto, que cabe ao revisor, como profissional da linguagem, compreender a atividade de revisão enquanto processo colaborativo entre revisor e autor do texto, cabendo ao primeiro ter conhecimento teórico suficiente para garantir a defesa de seu olhar 
profissional e proficiente para com o texto. Desse modo, sua tarefa poderá ser construída através de permanente diálogo com o autor, por meio da construção de sugestões embasadas e justificadas teoricamente, superando o "achismo" ainda comum em certas situações "profissionais". Suporte esse que pode ser encontrado nas bases da Teoria da Argumentação na Língua, a qual dispõe de fundamentos sólidos e consistentes que permitem ponderar sobre a boa organização de textos e comprovar aos autores das produções revisadas, normalmente leigos no conhecimento formal da língua, as justificativas que evidenciam os problemas encontrados e as possíveis maneiras de solucioná-los.

\section{A ANL e o trabalho do revisor: um exemplo prático de revisão textual}

Nesta seção, apresentar-se-á um excerto de um trabalho de revisão desenvolvido em um texto didático direcionado a alunos de um curso de graduação a distância em pedagogia de uma universidade federal localizada no extremo sul do país ${ }^{7}$. Na ocasião mencionada, o autor do texto enviou o material à equipe de revisão textual e, no momento do retorno de sua produção, houve conflito quanto ao que seria a construção textual adequada, bem como sobre o que seria uma intervenção linguística aceitável, conforme se pode observar nas sequências transcritas a seguir. Antes, porém, é necessário expor o fragmento do texto em sua versão original e a modificação realizada pelo revisor acompanhada da justificativa, conforme Quadro 1, abaixo:
A sequência desse episódio foi desenvolvida pela troca de seis e-mails entre o revisor tentando argumentar a favor de sua intervenção no texto, isto é, justificando-a para o autor do trecho transcrito e este, por sua vez, defendendo seu posicionamento sobre o que seria linguisticamente aceitável de um revisor de textos. Portanto, revisor e autor de texto revisado traçaram longo diálogo com vistas a tentar definir o que seria aceitável como parte do trabalho de um revisor de textos.

Primeiramente, pode-se afirmar que, se o profissional da revisão tivesse conhecimento dos pressupostos da ANL, poderia ter demonstrado na língua - isto é, por meio dos encadeamentos argumentativos e das relações entre as palavras - as razões de suas mudanças no texto, bem como dar a base teórica linguística cobrada pelo autor. Afinal, por meio da ANL, conforme será demonstrado a seguir, torna-se possível comprovar que os encadeamentos criados pelo autor são problemáticos e necessitam de modificação para não prejudicarem o sentido criado pelas relações estabelecidas no texto.

As palavras do autor para justificar a não aceitação das alterações elaboradas pelo revisor em seu texto demonstram que ele compreende a questão linguística do revisor como observação exclusiva dos aspectos gramaticais da linguagem, já que não vê o revisor com conhecimento profissional suficiente para intervir nas questões de estabelecimento de sentidos no texto, pois, como afirma: "Não quero que me leve a mal, mas a tua revisão é só da parte linguística e você pode e deve fazer sugestão, mas não pode reescrever o texto, mudando o sentido" (Autor do Texto revisado). Todavia, sabe-se que

Quadro 1. Exemplo da atividade de revisão textual

\begin{tabular}{|c|c|c|}
\hline $\begin{array}{l}\text { Excerto textual na versão original } \\
\text { escrita pelo autor }\end{array}$ & Excerto após intervenção do revisor & $\begin{array}{l}\text { Comentário inserido pelo revisor, } \\
\text { justificando as intervenções no } \\
\text { excerto do texto }\end{array}$ \\
\hline $\begin{array}{l}\text { "A instituição educativa contribui para o } \\
\text { fracasso escolar, mas não leva em consi- } \\
\text { deração a visão de mundo do aprendente. Por } \\
\text { outro lado, o aluno vive em um universo à parte } \\
\text { do universo escolar". }\end{array}$ & $\begin{array}{l}\text { "A partir das considerações precedentes, } \\
\text { pode-se concluir que a instituição educativa } \\
\text { contribui, em alguns casos, para o fracasso } \\
\text { escolar porque desconsidera a visão de mundo } \\
\text { do aprendente. Isso, consequentemente, } \\
\text { demonstra a discrepância existente entre o } \\
\text { universo da escola e o universo do aluno". }\end{array}$ & $\begin{array}{l}\text { "Prezado autor, há uma pequena alteração } \\
\text { na conclusão do texto, com a finalidade de } \\
\text { contribuir para o entendimento e o fechamento } \\
\text { das questões apontadas no decorrer da escrita. } \\
\text { Tendo isso em vista, aguardo seu retorno } \\
\text { e sua avaliação para dar prosseguimento ao } \\
\text { trabalho". }\end{array}$ \\
\hline
\end{tabular}

A resposta dada pelo autor do texto à intervenção demonstrada acima foi a seguinte:

Prezado Revisor, solicito que meu texto não seja reescrito como foi feito no último parágrafo, pois nem sempre o que você escreve é a intenção de quem escreveu até porque nosso campo teórico de formação é diferente! E com boa intenção pode-se alterar o sentido do texto. Não quero que me leve a mal, mas a tua revisão é só da parte linguística e você pode e deve fazer sugestão, mas não pode reescrever o texto, mudando o sentido (Assinado Autor do texto).

\footnotetext{
O material exposto foi cedido para pesquisa pelo autor à pesquisadora Vanessa Fonseca Barbosa, conforme assinatura do Termo de Consentimento firmado em dezembro de 2011. Parte do relato transcrito encontra-se na dissertação da pesquisadora mencionada, disponível em: <http://antares.ucpel.tche.br/poslet/dissertacoes/ Mestrado/2012/Uma\%20an\%E11ise\%20dia1\%F3gica\%20da $\% 20$ atividade $\% 20$ de $\% 20$ revis $\%$ E3o\%20lingu\%EDstica $\%$ o0EAD

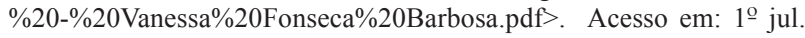
2014.
} 
com princípios teóricos sólidos seria possível demonstrar ao autor os seus equívocos textuais, fazendo-o perceber na língua os problemas e, consequentemente, as razões da reescrita, bases essas disponibilizadas pelos pressupostos da teoria francesa em foco neste trabalho, conforme será demonstrado.

Voltando ao exemplo transcrito no Quadro $1 \mathrm{e}$ considerando os postulados da teoria semântica argumentativa, pode-se formular os seguintes encadeamentos do excerto original, tal qual foi transcrito pelo autor do texto:

*a) Instituição educativa portanto fracasso escolar;

*b) fracasso escolar no entanto não considera a visão do aluno;

$\left.{ }^{*} \mathrm{c}\right)$ não considera a visão do aluno no entanto aluno à parte do universo escolar. ${ }^{8}$

Essas são as relações que aparecem no texto enviado para revisão. A partir dos encadeamentos apresentados pelo autor do texto, pode-se perceber que os sentidos veiculados no trecho demonstrado são confusos, uma vez que os conectores utilizados não explicitam as relações desejadas e os argumentos pretendidos pelo autor do texto.

No primeiro encadeamento desse discurso - instituição educativa portanto fracasso escolar - observase um problema linguístico. Diz-se isso porque, da maneira como está escrito o texto, o segmento instituição educativa está orientando para algo negativo. No entanto, não se espera de qualquer instituição educativa que contribua com o fracasso escolar, haja vista que, na língua, instituição escolar orienta para construção positiva do aluno, não para fracasso. Assim, embora o autor não utilize um conector explicitamente nesse bloco semântico, ele constrói o sentido do enunciado na relação entre os segmentos selecionados.

Como se pode observar, a primeira construção problemática do parágrafo terá consequência imediata no segundo encadeamento. Este - fracasso escolar no entanto não considera a visão de mundo do aluno - conforme elaborado pelo autor, é realizado por um conector de tipo transgressivo, o que demonstra que o sentido do encadeamento como um todo não é explicitado pelo autor do texto, uma vez que ele demarca a relação de sentido com um conector equivocado. Para além dessa questão, a própria relação entre as ideias está mal formulada, já que a não valorização do aluno, do modo como foi escrito, torna-se a causa do fracasso escolar.

A ideia que o autor do texto pretende expressar, a de que, por não considerar o universo do aprendente, a

\footnotetext{
8 Os asteriscos inseridos nos itens a, b e c indicam que as frases transcritas não são aceitáveis.
}

instituição formal de ensino estaria contribuindo para o fracasso escolar, deveria ser explicada por um conector normativo, pois, sob certas perspectivas teóricas, não considerar o universo que envolve o aprendente é não aproximar os conhecimentos manejados no ambiente formal de aprendizagem ao educando. Além disso, a própria relação entre os segmentos deveria ser revista, porque não é o fracasso que acontece pela não valorização da visão de mundo do aprendente, mas o contrário: é a não consideração que pode levar ao fracasso escolar porque o aluno não se identifica com o que aprende. Assim, desconsiderar os saberes do aluno orienta para fracasso escolar do estudante.

Dessa forma, para a construção do sentido que o autor do texto pretendia edificar a partir da relação entre os segmentos, seria necessário alterar o conector transgressivo por um normativo, além de reorganizar a relação entre os elementos do enunciado. $\mathrm{E}$ foi isso que $\mathrm{o}$ revisor fez, ao reescrever o trecho analisado: construiu o seguinte resultado: "Por não considerar a visão de mundo do aprendente, em alguns casos, a instituição educativa contribui para o fracasso escolar" (Revisor).

Destaca-se também que, admitindo-se que haja uma instituição educativa que tem contribuído para o fracasso escolar e que isso ocorre, sobretudo porque tal espaço desconsidera a visão do aluno, consequentemente, não se pode afirmar: fracasso escolar portanto dois universos distintos. Tal assertiva justifica-se pelo fato de que fracasso orienta para algo negativo, no caso específico, para a desconsideração do outro, sujeito aprendente, logo, o conector deveria ser do tipo transgressivo, não normativo tal como fora escrito.

Dessa maneira, para melhor organização do texto, conforme foi sugerido na revisão mostrada no quadro anterior, têm-se os seguintes encadeamentos:

a) instituição educativa no entanto fracasso escolar;

b) considerar a visão do aluno portanto não fracasso escolar;

c) não considerar a visão do aluno portanto aluno à parte do universo escolar.

Assim, diante da breve análise realizada e no encontro da comprovação teórica, percebe-se que o excerto textual apresenta problemas linguísticos de organização. No entanto, a afirmação do revisor de que "há uma pequena alteração na conclusão do texto, com a finalidade de contribuir para o entendimento e o fechamento das questões apontadas no decorrer da escrita" pode ter sido muito abrangente e não ter passado segurança suficiente para convencer o autor das alterações realizadas pelo revisor.

Consequentemente, o autor insiste em não aceitar as modificações em seu texto, ainda que, como se observou, este estivesse organizado sob a sequência de 
frases soltas, que não se relacionavam adequadamente na e pela linguagem. Daí decorre a grande importância de conhecimento da Teoria da Argumentação na Língua, haja vista que ela daria as bases necessárias para solucionar os problemas existentes, através da comprovação linguística que, certamente, não deixaria dúvidas no autor para aceitar os ajustes textuais necessários à coerência teórica.

$\mathrm{O}$ excerto transposto é pequeno, mas possibilitou demonstrar o objetivo deste trabalho que é o de refletir sobre como a ANL pode potencializar uma produção textual e, em consequência, contribuir significativamente para o trabalho do revisor de textos e para o seu diálogo com o autor dos textos revisados. Antes de finalizar, torna-se imprescindível dizer também que o exemplo transposto não teve por objetivo expor negativa ou pejorativamente a figura do autor do texto como alguém que não sabe escrever. Pelo contrário, buscouse expor o quanto é complexo o processo de escrita e quantas dificuldades se pode encontrar, enquanto autor de determinado texto, pois, muitas vezes, justamente por se estar imerso no material escrito, não se tem o distanciamento necessário para perceber que nem sempre o que se gostaria de dizer é o que está dito, tendo em vista o arranjo linguístico das palavras. Nesse sentido, a atividade de revisão é muito válida, já que, por contar com o privilégio do distanciamento, pode-se ter o tempo de maturação necessário para a reorganização linguística, o que, certamente, potencializará a escrita.

\section{Considerações finais}

O presente artigo buscou discutir questões que interessam aos profissionais da área de Letras, mais especificamente àqueles que atuam ou pretendem desenvolver atividades como revisor de textos. $\mathrm{O}$ assunto demonstra sua relevância na medida em que essa é uma das áreas do curso de Letras com grande procura pelo mercado de trabalho, ainda que de modo informal na sua maioria.

Assim, apresentou-se na Teoria na Argumentação da Língua uma possibilidade de ancoragem teórica satisfatória para o trabalho com revisão textual principalmente no que diz respeito a uma ancoragem teórica que dê sustentação para a atividade do revisor e o diálogo com o autor do texto revisado. Talvez, uma das grandes diferenças entre a revisão de um professor de produção textual no texto de um aluno e a de um revisor profissional, ainda mais o que trabalha com textos acadêmicos, esteja no fato de que o primeiro quase nunca é solicitado a justificar os problemas que encontra no texto, enquanto o segundo, se não sabe justificá-los de modo preciso e coerente, perde totalmente sua voz e sua "autoridade" no trabalho que realiza.

\section{Referências}

CORDERO, Nestor Luis. Introduction. In: PLATON. Le Sofhiste. Paris: Flammarion, 1993. p. 12-65.

DUCROT, Oswald. Primera conferencia. Polifonía y argumentación. Cali: Universidad del Valle, 1990. p. 49-64.

DUCROT, Oswald. Argumentação retórica e argumentação linguística. Letras de Hoje, Porto Alegre, v. 44, n. 1, p. 20-25, 2009.

DUCROT, Oswald. A descrição semântica em linguística. In: O dizer e o dito. Campinas: Pontes, 1987. p. 45-62.

DUCROT, Oswald. Estruturalismo, enunciação e semântica. In: $O$ dizer e o dito. Campinas: Pontes, 1987. p. 63-88.

DUCROT, Oswald. Conferencias 1 e 2. La Semántica Argumentativa: una introducción a la Teoría de los Bloques Semánticos. Buenos Aires: Colihue, 2005. p. 11-50.

SAUSURE, Louis de. La Sémantique Argumentative peutelle se réclamer de Saussure? Nouveaux regards sur Saussure. Genève: Droz, 2006. p. 153-170.

SAUSSURE, Ferdinand de. Curso de linguística geral. São Paulo: Cultrix, 2012.

Recebido: 30 de novembro de 2014

Aprovado: 11 de fevereiro de 2015

Contatos: barbisan@pucrs.br mtamiris@gmail.com vanessa.barbosa@acad.pucrs.br 